\title{
Japan's Most Famous Surveyor: \\ Ino Tadataka and His Iconic 1821 Map of Japan!
}

John F Brock

Registered Surveyor (NSW, Australia) Brock Surveys Pty. Ltd.

P.O. Box 9159,

HARRIS PARK NSW 2150, AUSTRALIA

Tel: +61(0)414910898

Email: brocksurveys@bigpond.com

\begin{abstract}
:
Having examined famous surveyors and surveys from all over the world it is not often that I have encountered a country that was so proud of one of its legendary surveyors that they struck a postage stamp to him for his survey work. However, I was absolutely delighted when I discovered that the Japanese nation had dedicated an 80 yen postage stamp to their hero surveyor Ino Tadataka who had been responsible for surveying the country to provide the details for the first accurate map of its territory in 1821. Even though this large chart was published posthumously he is rightly celebrated as the genius behind this masterpiece of cartography having spent the last seventeen (17) years of his life personally walking and measuring the entirety of its coastal boundaries from the advanced age of 55 years.
\end{abstract}

Within this paper I will trace the life of this great man highlighting the Edo Period of Japanese history along with the techniques and surveying equipment utilized by Ino and his survey teams to collect the measurements required to produce the first accurate delineation of the coasts of their nation. Along the way we will visit Ino's house and various museums and statue monuments honouring this surveying hero and his truly remarkable achievements in precise mapping during a time before GPS, drone and aerial photogrammetry and remote sensing from satellites.

\section{Keywords:}

Early Japanese surveying, Edo Period, Japan’s Most Famous Surveyor, Ino Tadataka, 1st Accurate Map of Japan 1821

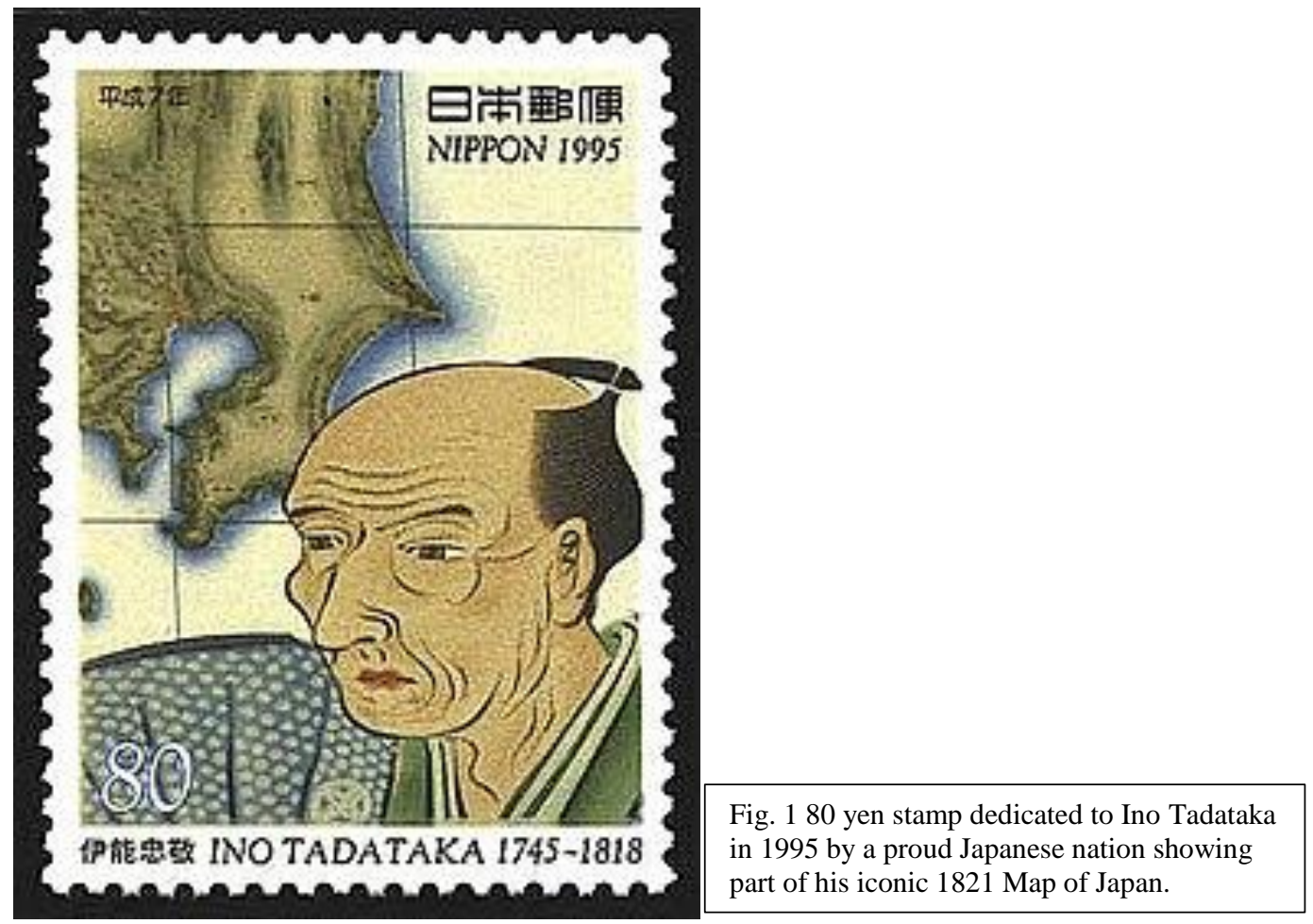




\section{Introduction}

During the Edo Period (1603-1868) Japan's militaristic government had adopted an exclusionist policy on fraternisation with foreign nations except The Netherlands and parts of China which formed significant obstacles to scientific advancement with regard to surveying equipment, modernising techniques of calculation, calendar reformation and summary other issues undergoing transformation such as measurement standards including geodetically precise mapping procedures. There was even a prohibition imposed on surveying in public streets or areas designated inappropriate by the martial law invoked by the authoritative powers controlling all aspects of human life in their country.

\section{Ino's Early life up to age 50}

Ino Tadataka was born into most humble beginnings in what is now the northern Chiba Prefecture nearby to Narita International Airport. Born with the name Chukei ne Sanjiro on February 11 in 1745 he was the youngest of three children to Sadatsune Jinbo, the third son of the village officer of Onzumimura in the Province of Kazusa. Upon the death of his mother at the age of six Chukei's father took the two older children back with him to his biological family, having been residing with an adoptive family during the previous time, but left Chukei behind. Not much is known of Chukei in this early period except that his great acuity with numbers was noted but, having little time for study, his time was occupied in a bait and tackle shop at Kujukuri Beach on the Pacific coast.

At some time during this era he is believed to have learnt maths and medicine from a local priest for six months, then under another tutor, as the mastering of maths and medicine was said to be a route to distinction even for those of common ancestry. At age 10 his father came to bring him back to live with the Shinbo family with his next major windfall coming at the young age of 17 when he was plucked from oblivion to marry into the Ino family which was a wealthy local clan in the Sawara region which had business in rice, sake and shipping, at its peak owning thirty six (36) breweries in Sawara. The family was also a major land owner in the district. As was the custom upon his marriage to the young heiress Michi (who was actually slightly older than him) he was rechristened Ino Suburoemon Tadataka with the middle name the hereditary name assumed by all heads of the Ino family and Tadataka his given name.

As the head of the village and the top man in the family organisation Ino never allowed the temptation of power and wealth to corrupt his benevolent values. As a result of his generosity and kind caring nature the people of his village held him in most high esteem especially when he saved them from starvation during a rice famine then when the taxing authorities imposed an unfair levy on the desperate farmers, he and another family member paid for all of the expenses.

During the period while he was the head of the village of Sawara he had taught himself how to do land surveying from the Japanese texts "Ryochi-shinan", "Kikubuntoshu" and "Choken-bengi" which allowed him to define the boundaries of the farms in the village. Making several maps of the village and plans of his dwelling in 1792 and 1794 he had already demonstrated his competence as a land surveyor and many of these maps and plans are still preserved today. Evidence survives that reveal the instruments he utilised for surveying around this time were the gnomon, magnetic compass (circumferentor) and simple vertical circle, none of which were fit for precise mapping usage.

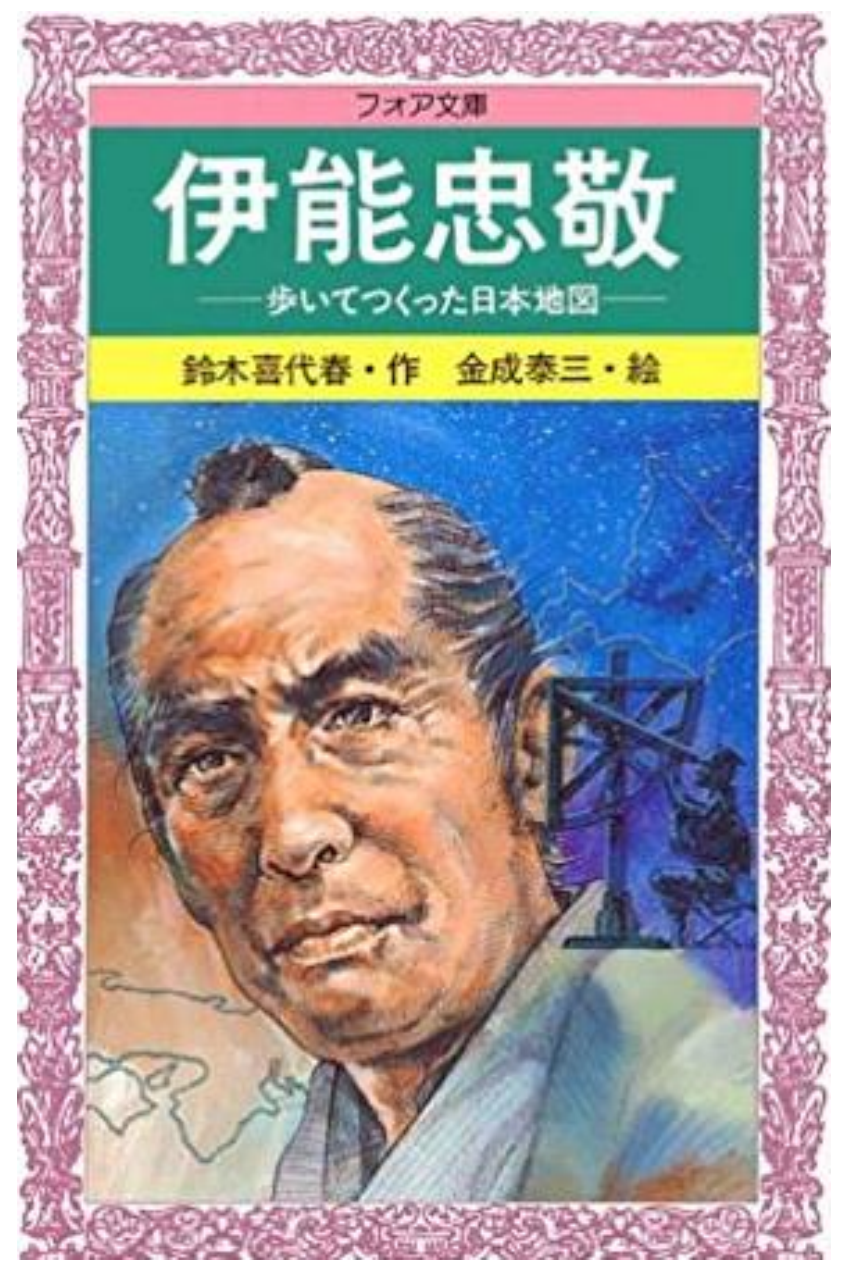

Fig. 2 Portrait of Ino from a book cover. 


\section{Reaching the age of surveying enlightenment in the Edo Period}

During our modern ages when someone attains the age of 50 it would not be regarded as the time for retirement but during Ino's life the average age of death was only around 50 ! Thus Ino's decision to retire at 50 was not unusual but in his circumstances it merely provided him with more freedom during which he could learn how to achieve an answer for a problem which had perplexed the scholars of the world for thousands of years - the real shape of the earth. However, many major obstacles confronted Ino on his quest to resolve this scientific enigma, such things which modern scientists take for granted when seeking answers to features associated with measurement, time, longitude, terrestrial magnetism and a whole host of puzzling parameters existing for Ino and his colleagues.

One of the main disadvantages for Ino and his sensei Takahashi was the Isolationist Policy imposed by the militaristic ruling class of the Edo Period (1603-1868). It was only in 1720 that it was allowed for elite scholars to obtain copies of Western texts on astronomy and science, and most of these volumes were in Dutch or Chinese so linguistic versatility was essential for the Japanese academics to open themselves up to the discoveries of their Western counterparts. It was only at the latter part of the $18^{\text {th }}$ century that the navigational problems with longitude determination through the proven success of Harrison's Chronometer No. 4 finally gifted to the mariners when James Cook field tested the device using a perfect copy being a Kendall No.1 on his second round the world voyage (1772-75) in the Resolution, in company with the Discovery commanded by Furneaux. Not only had longitude been hard to crack there was the differing calendars which were adopted by the various civilisations which caused miscorrelation with Astral, Solar and Lunar Almanacs compiled for the prediction of celestial events for use in accurate latitude, longitude and azimuthal determinations. Add to all of this that just about every nation had its own standards in measurement, weights and anything else for which in the current era we can thank the world standards authorities for setting fixed measurements in feet or metres, weights in pounds or kilograms and volumes in pints and litres. Virtually the only unsolved curiosity of modern times is terrestrial magnetism with its irregular magnetic variation being described by the exceptional physicist Albert Einstein as one of the top five problems in physics!

Just when you thought that there couldn't possibly be any more barricades to Ino's progress to achieve mapping level accuracy it has to be understood that Ino did not have full access to the wider scientific instrument market consequently being forced to have most of his surveying and astronomical devices made by Japanese makers! What a miraculous accomplishment all of Ino's feats were in the face of all of this multitude of dilemmas. Without missing a beat or complaining he carried on unperturbed.

\section{Looking to the stars with Sensei Takahashi}

Upon his retirement from the family enterprises at the age of 50 he moved to Edo and sought out the astronomy master Takahashi Yoshitoki with whom he sought to apprentice himself to learn the skills of astronomical ground determinations through his mentor's tutelage in Western arithmetic, physics, astronomy, geography, and land surveying. Both men were skilled in reading the Dutch language along with knowledge of Chinese thus being able to teach themselves the discoveries of Western and Chinese mathematics and science. Takahashi, along with the instrument maker Hazama Shigetomi had been ordered by the Shogunate on 18 March 1795 to depart Osaka to be based at the Astronomical Bureau office in Edo.

Under the personal mentorship of Takahashi, Ino learnt how to use astronomical observations to fix his geographic position upon the earth's surface precisely, so after his five-year internship he was inspired to make a determination of one degree of arc to determine the real size and shape of the earth. With this singular ambition driving him forward it was not surprising that he took the next step under the motivation of his star master which was to make an accurate map of Japan for the ultimate benefit and utilisation of the whole nation as, up until that point, there were no maps or charts which portrayed the true coastline of Japan. Ino was the first man in Japan to observe the meridian passage of Venus during the day in 1797 and by the time of the completion of his five years training he had also acquired more scientific instruments of superior quality to give him the capability to carry out more precise observations to achieve the mapping accuracy required for his giant map.

\section{Walking 40 million steps to survey Japan}

The distance walked by Ino to complete his great Map of Japan is estimated to be 40,000 kilometres which is equal to $40,000,000$ metres equalling the circumference of the earth from pole to pole. Thus, with a human step around 3 feet ( 0.915 metre) with a little bit of imagination and some creative scaling it could be approximated to around 40 million steps so the description can assume a plausible basis. The total coastline of Japan divided into its five districts of Honshu, Hokkaido, Kyushu, Shikoko and Okinawa, is $29,751 \mathrm{kms}$ so Ino's total traverse length adding side excursions to parts of the inland, such as Mt. Hakodate, a broad estimation of 40,000,00 metres is fully credible.

His project took place in two major stages - The Eastern portion and the Western portion - in ten (10) Survey Expeditions. Survey No. 1 was started with five crew members on $11^{\text {th }}$ June 1800 for Tohoku in Southern Hokkaido to chart the areas where Russian ships were coming to open trading establishments. The survey was made entirely by pacing and intermediate astronomical 
observations reaching Bekkai in far northeast Hokkaido traversing 3,244 kilometres. Ino's personal reserves funded this survey but the Bakufu government realised the importance of this work, rendering more support for his second expedition, which left Tokyo in summer 1801. This part of the survey lasted 6 months covering from just south of Tokyo to the far north point of Honshu then measuring the interior on their return representing 3,122 kilometres. The third route measured Western Tohoku in 1802, the fourth section in 1803 spread between Tokai and Hokuriku, all of which was heavily subsidised by Ino himself. After submitting his Map of Eastern Japan in 1804 to the government, the Shogun Tokugawa Ienari was eminently impressed, making Ino a Shogunate official. From this time onwards the final six mapping sections were paid for by the Tokugawa Shogunate. These took place in this order:

Survey \#5 - Kinai/Chugoku. 1805-06

Survey \#6 - Shikoku, 1808-09

Survey \#7 - Kyushu Part 1, 1809-11

Survey \#8 - Kyushu Part 2, 1811-14

Survey \#9 - Izu Islands, 1815-16 (Ino did not attend)

Survey\#10 - Edo, 1816.

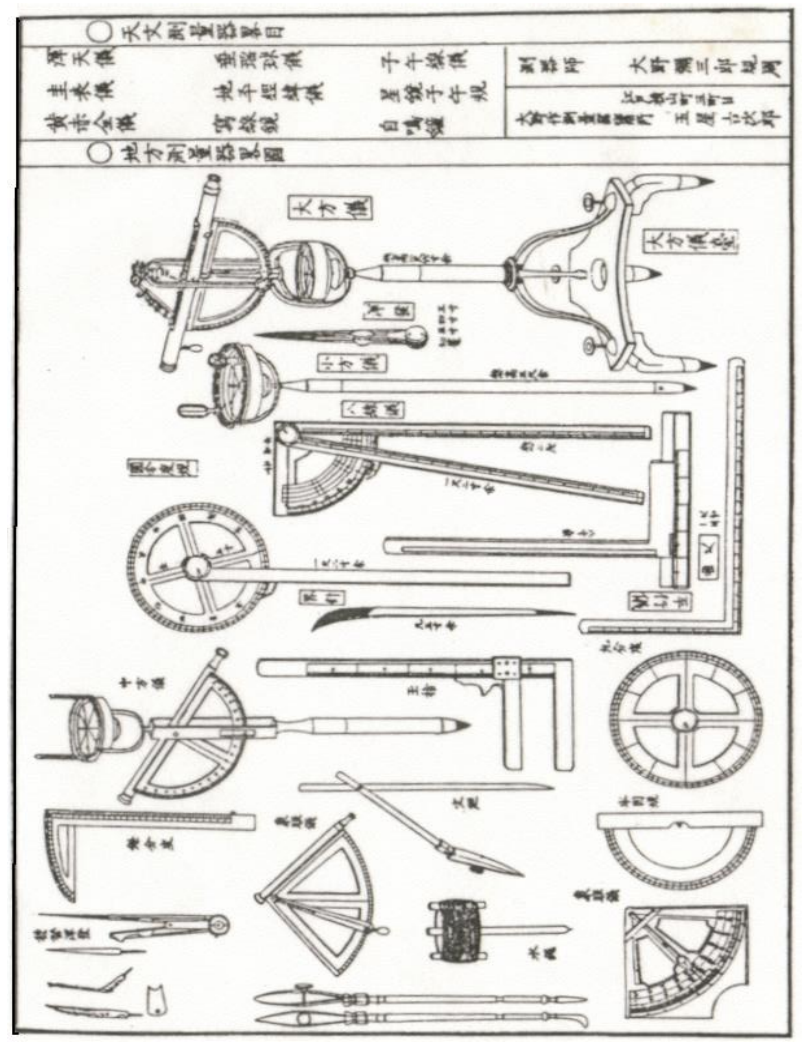

Fig. 3 An extensive Corpus of Japanese surveying instruments available to Ino and his team.

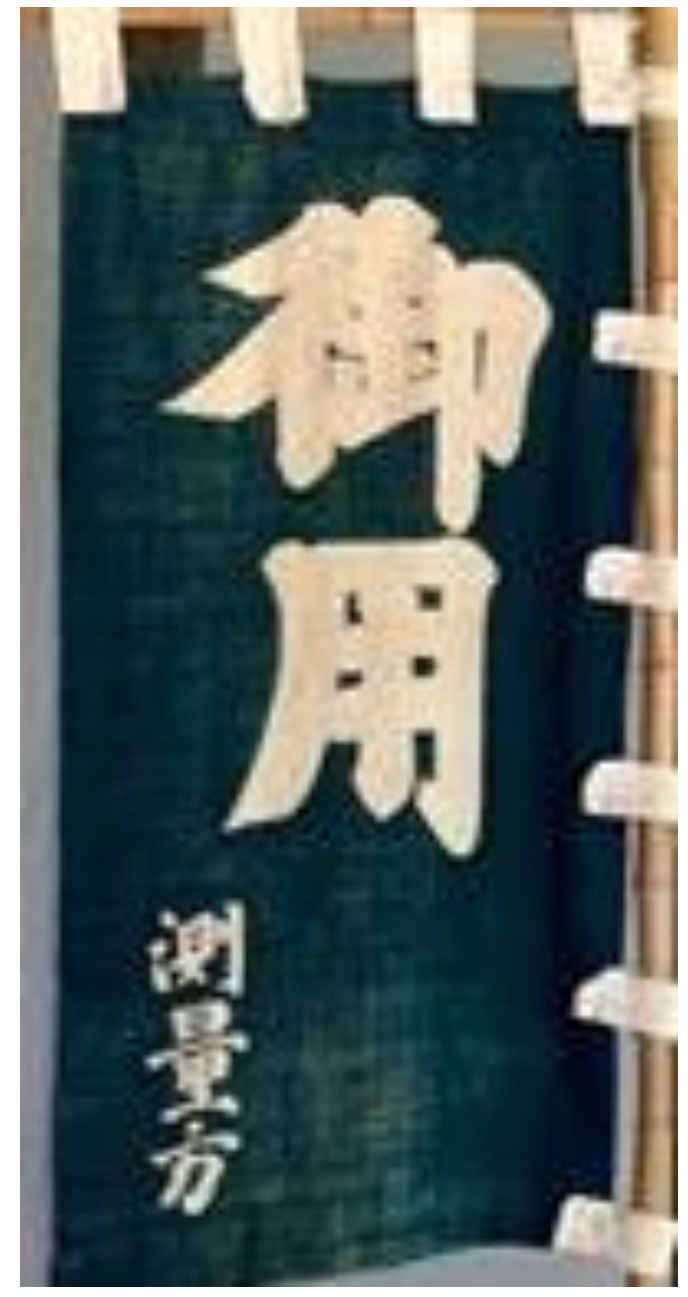

Fig. 4 Ino Survey Team flag

Although Ino had been present for nine of the ten expeditions before the ninth survey he contracted malaria, but his survey team carried on (literally!) without him. Unfortunately, they engaged in loutish misbehaviour without his leadership causing Ino to dismiss one of his most loyal retainers, Hirayama Gunzo, to set an example to the rest of the carousers and drunkards. The only part of the Japanese nation not included in Ino's 18 year marathon was the Okinawan Islands. Ino's last field work on his great project was the surveying of Edo in 1816. Finally, after some years of respiratory discomfort, Ino died in his house on Kamejimacho at the age of 73 years on 17 May, 1818 from chronic bronchitis. Just prior to his passing Ino said: "My accomplishment of the great task of surveying Japan and my present reputation are due to the guidance and instruction of my teacher, Mr. Yoshitoki Takahashi. So I wish my remains to be buried beside the grave of my teacher, in token of the great debt I owe him." Thus the sensei and star pupil now lay side by side in the graveyard of a temple known as Genkuji, Kita-Kiyoshima-cho, Asakusa, the gravestones sincerely revered by a most grateful populace. 


\section{Ino's survey method depolarises magnetic azimuth and declination}

One curious factor to beset Ino's quest for precision was the variable magnetic declination of the Earth's magnetic field. I would like to wager that Ino was very aware of this variable while he traversed the countryside with magnetic theodolites because he states that the magnetic declination was negligible during this period of Japanese history and when I found a source which showed a chart of the amount of this figure in 1800 it was indeed quite close to zero for the entirety of Japan. The current variation from West to East for this island nation ranges from the western port of Kakinora at latitude $33^{\circ} 01^{\prime} 37.5^{\prime} \mathrm{N}$, longitude 129 $33^{\circ} \mathrm{E} @$ $-7^{\circ} 22^{\prime}$ (west) to Tachiniusu on the west coast of Hokkaido at latitude $43^{\mathrm{O}} 58^{\prime} \mathrm{N}$, longitude 145'19'40' $\mathrm{E} @-8^{\mathrm{O}} 59^{\prime}$ (west). In Australia as at 2019 the magnetic declination ranges from zero $(0)$ on the western coast to about minus 14 degrees (west) near Sydney across a longitude difference of nearly $40^{\circ}$. As Ino's survey method was devised as an unclosed traverse he was able to adjust out any slight errors due to the curvature of the earth and terrestrial magnetism plus systematic errors in his surveying instruments by keeping the end points of his lines controlled by way of precise ground positioning through astronomical ground fixes which were a continuing input to the accuracy of the mapping. It is said that the extremities of his map show some slight distortions in longitude towards the east, this effect being attributed to the fact that at that time Japan did not have accurate clocks so Ino calculated his longitudes mathematically. Another contributing element requiring maintenance for the reliability of his survey traverse was the specification of accuracy applicable to the reading of magnetic bearings from a circle without optical magnification thus producing azimuths which could only be accurate to about twenty (20) minutes of arc. Such a random error could be swallowed up in the adjustment of the traverse network between the precisely positioned astro stations so this issue was counteracted through the continuous adjustment of the survey figure.

The survey instruments employed on the standard survey traverse were listed as:

A/ A Measuring Scale;

$\mathrm{B} /$ Measuring Pole;

$\mathrm{C} /$ Measuring Rope - as well as a

bamboo rattan and Gunter's chain;

D/ A Perambulator;

E/ Magnetic Compass;

F/ Small Magnetic Theodolite;

G/ Semi-Circular Magnetic

Theodolite;

H/ Middle and large size Magnetic

Theodolites;

I/ Small Quadrant as an Inclinometer.
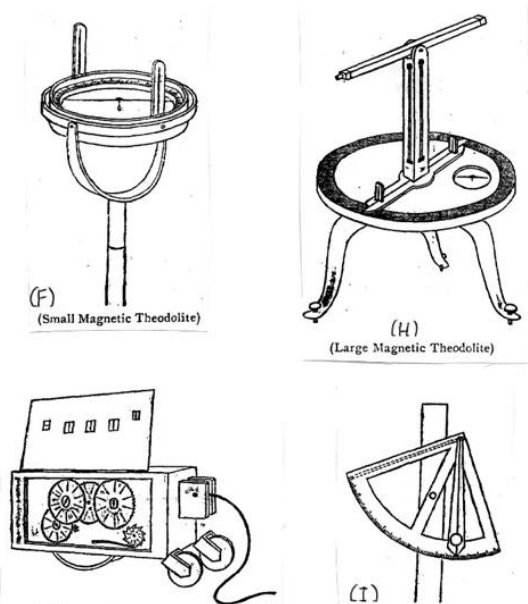

(D) (Measuring When
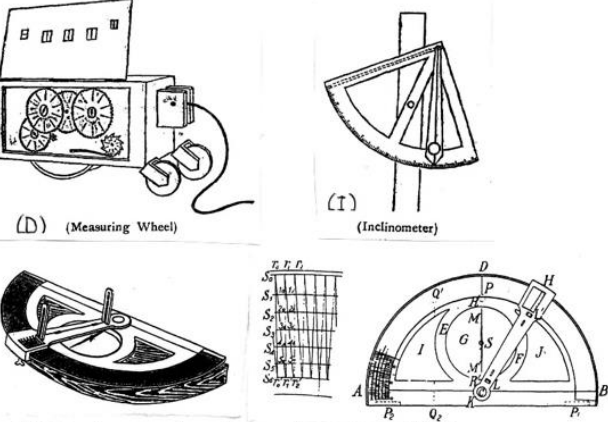

(G)(Semi-Circular Magnetic Theodalite)

Fig. 5 Sketches of some of Ino's Survey Instruments used in the ground survey traverse.

Astronomical equipment said to have been used by Ino is as follows:

A/ The Quadrant;

B/ The Transit Instrument

C/ The Pendulum Clock;

D/ The Eclipsemeter;

E/ The Gnomon;

F/ The Telescope.
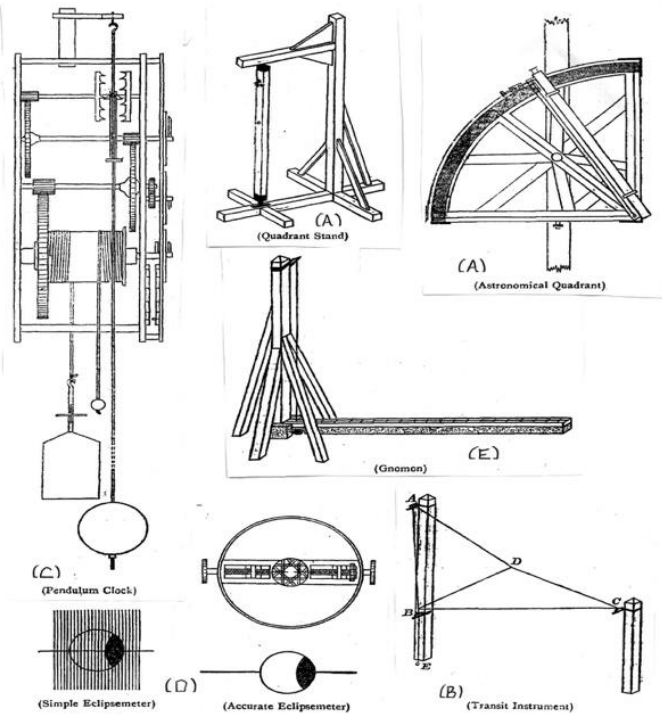

Fig. 6 Astronomical Scientific Instruments used by Ino to make precise position observations for the maintenance of accuracy throughout his mapping expeditions. 
For more detailed explanations of the functions of each of these devices please refer to the brilliant book "Tadataka Ino: The Japanese Land-Surveyor" by Ryokichi Otani (2001). Ino's numerous observations, calculations and network adjustments are preserved in many bound volumes of books so his techniques and results are chronicled as true testimony to his brilliance and thoroughness for one of the most incredible surveying and mapping feats in the history of cartography.

\section{Ino's adopted standard of measurement}

At the time of Ino's mapping exploits there were a varying number of lineal measurement standards existing among the assorted trades and professions who worked in careers dependent upon mensuration to perform their everyday activities in his country alone!

Enshrined within the Daiho Statute, which was issued in $702 \mathrm{AD}$, the standard measure known as the shaku was handed down from generation to generation finally to reach the Shogun Yoshimune Tokugawa who divinely decreed that, through consultation with ancient documents, he introduced a new scale as a duplicate of the small scale of Daiho preserved in the ancient storehouse of the Kumano Shrine. It was named the "Kyoho-shaku." However, since the Shogunate did not rigidly enforce either of these lineal standards there also existed two other distance bases used by manufacturers and by the carpenters, the former known as the "Nembatsu-shaku" (equivalent to the Kyoho-shaku) and the latter the "Matashiro-shaku" being slightly shorter than the previous measure. The tradition which survives in literature states that Ino adopted a measuring scale which was the mean of the Kyoho-shaku and the Matashiro, his distance being 2 rin shorter than the first and 2 rin longer than the second. In a manuscript compiled by the Department of Agriculture and Commerce it was written that, when the weights and measures were fixed by law in 1875, Ino's scale was adopted for the legal standard corresponding to 0.30303 metre when compared to the metric system in 1880. The current day length of the legal unit in Japan equates exactly with the one adopted by Ino for his great survey. Most individuals conversant with measurement can identify that Ino's standard length unit is exceptionally close to the British Imperial foot of 0.3048 metre so his judgement would appear to have been impeccable in any area of mathematics or science within which he chose to focus himself.

\section{Ino's map projection for the map and atlas of 1821}

Keeping in mind the more northerly position of japan in the Northern Hemisphere it is not surprising that, for the representation of his map plot, Ino chose a map projection which would more truly depict the shape of his nation. At latitudes roughly from 33 degrees to 44 degrees there are noticeable distortions present in a normal Mercator Projection as the figure of the world is cast onto a cylinder which is tangential to the Equator. Therefore, the further north the land mass is the greater the deformations are, mainly in the northerly proportions. Our Japanese hero wisely chose a Sanson-Flamsteed Sinusoidal Map Projection, otherwise referred to as a pseudo-cylindrical Mercator Projection which has the lines of latitude parallel to each other while the lines of longitude are curved and convergent in not a dissimilar manner that these map lines appear on the surface of equal area Projection which has the lines of latitude parallel to each other while the lines of longitude are curved and convergent in not a dissimilar manner that these map lines appear on the surface of the Earth

The Prime Meridian adopted by Ino for his map was through Kyoto at longitude $135^{\circ} 45^{\prime} \mathrm{E}$ (GMT +9 hours) and a latitude very close to $35^{\circ} \mathrm{N}$. This PM line is not far from the middle between the eastern and western limits of Japan's coastline which are $129^{\circ} 35^{\prime \prime} \mathrm{E}$ and $145^{\circ} 20^{\prime} \mathrm{E}$.

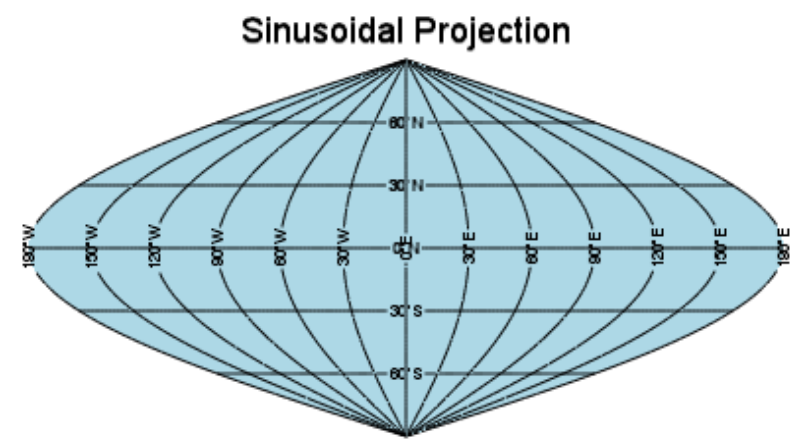

Fig. 7 Ino's Chosen Map Projection: The Sanson-Flamsteed Sinusoidal Map Projection.

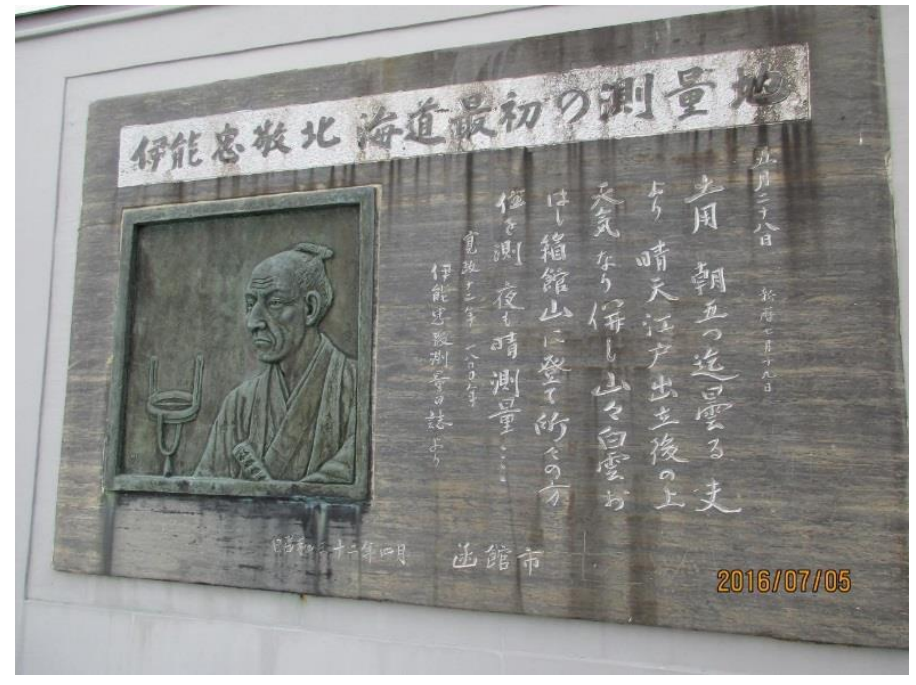

Fig. 8 Monument to Ino on top of Mt. Hakodate on the southern tip of Hokkaido at the location he occupied one of his survey traverse stations. 


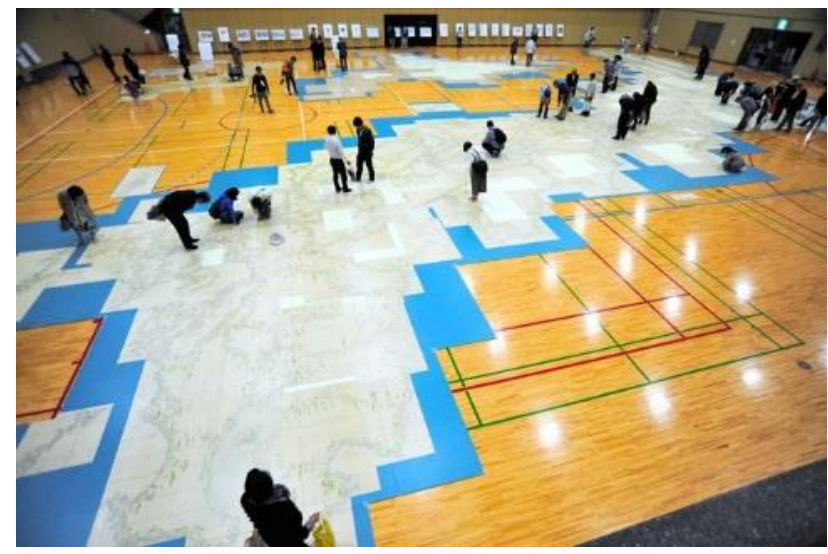

Fig. 9 Ino's Large Map @ 1:36,000 measuring 47 by 45 metres laid out on the floor of a modern gymnasium.

Despite Ino's death in 1818 his survey team eventually completed the final accurate Map of Japan in 1821. The large scale map comprised 214 sheets at the scale of 1:36,000 occupying an area of 47 by 45 metres (see figure $8)$, the medium sized map in eight (8) sheets was @ $1: 216,000$ while the smaller version came in three (3) sheets@1:432,000. Along with these exceptional plan compilations an atlas was also produced containing the same complete sequence of map sheets as those making up the three differently scaled maps. The atlas was named Dai Nihon Enkai Yochi Zenzu (meaning Maps of Japanese Coastal Areas).

\section{Surveying books made by Ino}

Not only was Ino a diligent keeper of records of his observations, calculations, field work and landscape sketching he also found some spare time (?) to edit some texts on surveying. His publications are named below:

1/ The Sokuryo-nikki (diary of surveying) in 28 volumes, recording the conduct of his surveying from 1800 to 1816 in minute detail;

2/ The Santo-horki (record of the magnetic azimuths of mountains and islands) in 70 volumes, of observations to these objects using various types of magnetic theodolite from occupied survey stations which provides valuable data for historical evolution of magnetic declination from the early $19^{\text {th }}$ century;

3/ The Hokkyoku-kodu-sokuryoki (record of latitude measurements) being a record of observed differences between the meridian altitudes of fixed stars from stations used and the base in Yedo;

4/ The Kosei-shikodu-hyo (star catalogue giving apparent altitudes) containing Ino's personal observations made at the control station at Yedo;

5/ The Kokugan-chuya-jikoku (various lengths of day and night) in 2 volumes listing sunrise and sunset times as well as twilight duration;

6/ The Taisuhyo-kigenjutsu-narabini-yoho (method of construction and usage of a logarithm table;
7/ The Ino-Toka-ryu-ryochi-denshuroku (Ino's manuscript on land surveying) in 2 volumes, written by Ino's pupil Keijiro Shin Watanabe, after his death and in accordance with his will;
8/ Chikyu-sokuenjutso-mondo;
9/ Kyukatsu-en-hassenho

\section{Modern commemoration of Japan's greatest surveyor}

The incredible mapping exploits of Ino Tadataka are commemorated widely even today, over 200 years since his passing, with the regular performance of the stage play "The Man Who Walked Forty Million Steps" by the renowned Japanese playwright Inoue Hisashi, first performed in 1986. His amazing story has been the subject of documentaries and television series as well as making its way onto the cinematic screens in a 2001 movie titled: "Ino Tadakata: The Dream of the Meridian" starring Kato Go and singer Nishida Hikaru.

The inspiration derived from Ino's superhuman success has been channelled into an animated promo-commercial for a TV show called Yume no Tobira (translated as "Gateway to Your Dreams") aired on the popular Tokyo Broadcasting System (TBS) with the catchy motto "no matter how old you are, you should never give up on your dreams."

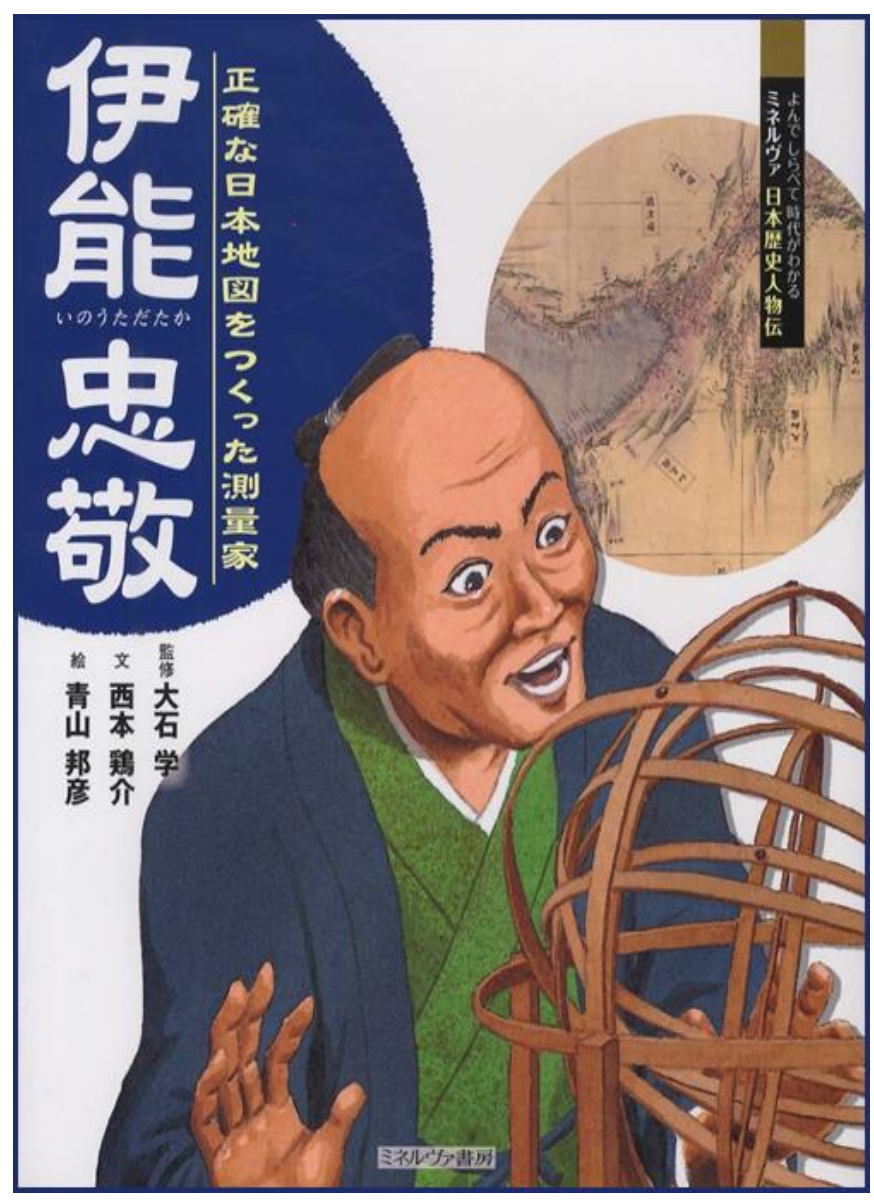




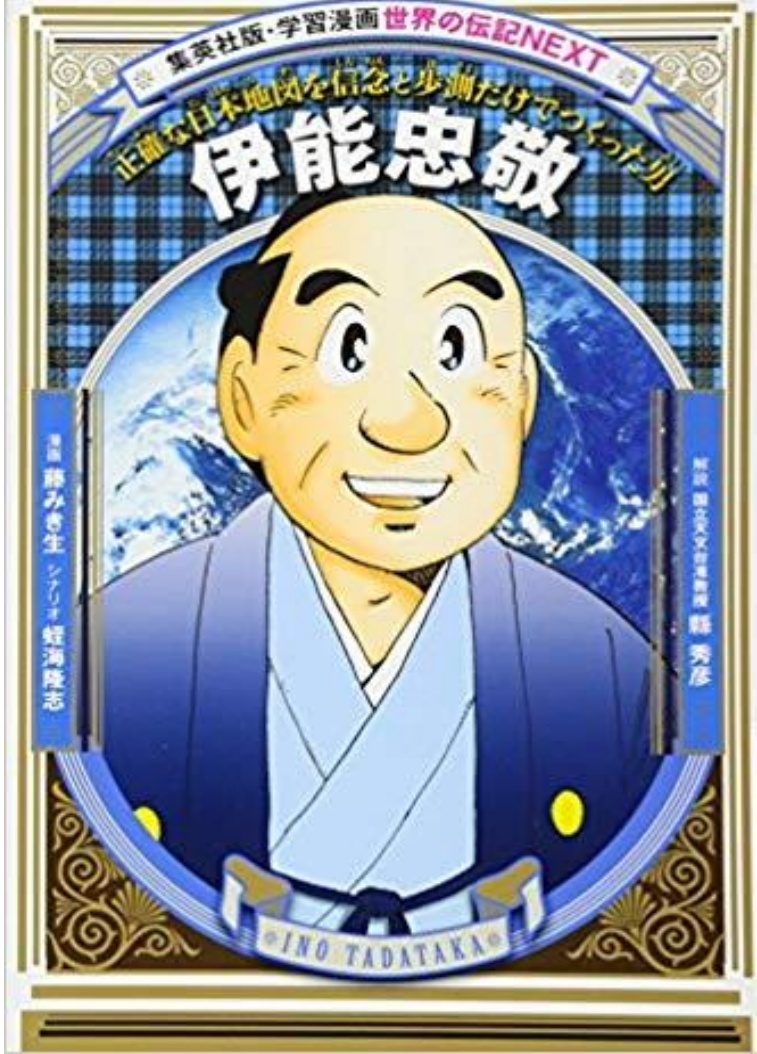

Fig. $10 \& 11$ Ino depicted as a cartoon in the world of Japanese animation of today.

You know when an historical character has captured the modern imagination when they are transformed into a cartoon just as Ino has undergone this prestigious metamorphosis into the world of animation in his home nation of Japan. Ino is a popular image in the Japanese cartoon business. Modern day Japanese still revere Ino as a national hero with statues and plaques commemorating his monumental survey of Japan over 17 years and even his home in Sawara has been preserved (see fig. 12) and listed as a national heritage monument. Nearby to his residence is The Museum of Inoh Tadataka which houses many of his surveying and drawing implements as well as fine examples of some of his high quality cartography. It is on my itinerary for visitation while I am in Japan attending this most eminent International Cartographic Conference for which I am exceptionally grateful to have the distinction to make this presentation.

One final proof beyond doubt that Ino has entrenched himself in local Japanese culture is that there is even a type of tea made to honour him - Chukei-gonomi which translates as "Chukei Style Tea", which is obtainable from one of the Inou family tea dealers called Ohtakaen with an outlet in Sawara near the Little Edo Sawara boat tour kiosk.

\section{Conclusion}

There is no doubt that the precision of mapping achieved by Ino was remarkable but when the method of transportation and quality of the surveying instruments available at that time are considered the 1821 Map of Japan was truly a cartographic marvel. Along with the widespread benevolence of Ino to his community and his advanced age at the commencement of the mammoth task Ino stands tall with all of those who have achieved greatness without the luxury or benefit of being born into wealthy surroundings. To be immortalised in a stage play called "The Man Who Walked Forty Million Steps" encapsulates his amazing accomplishments and, if I may declare, Ino Tadataka is not just a Japanese Hero, because he can rightfully assume his place as one of the World's Greatest Heroes... And he was a Surveyor!

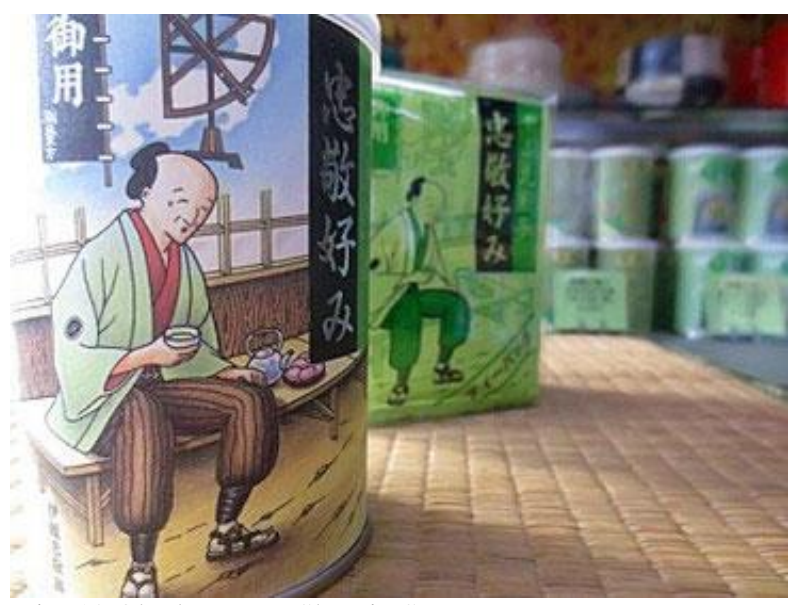

Fig. 12 Ohtakaen Tea Shop in Sawara

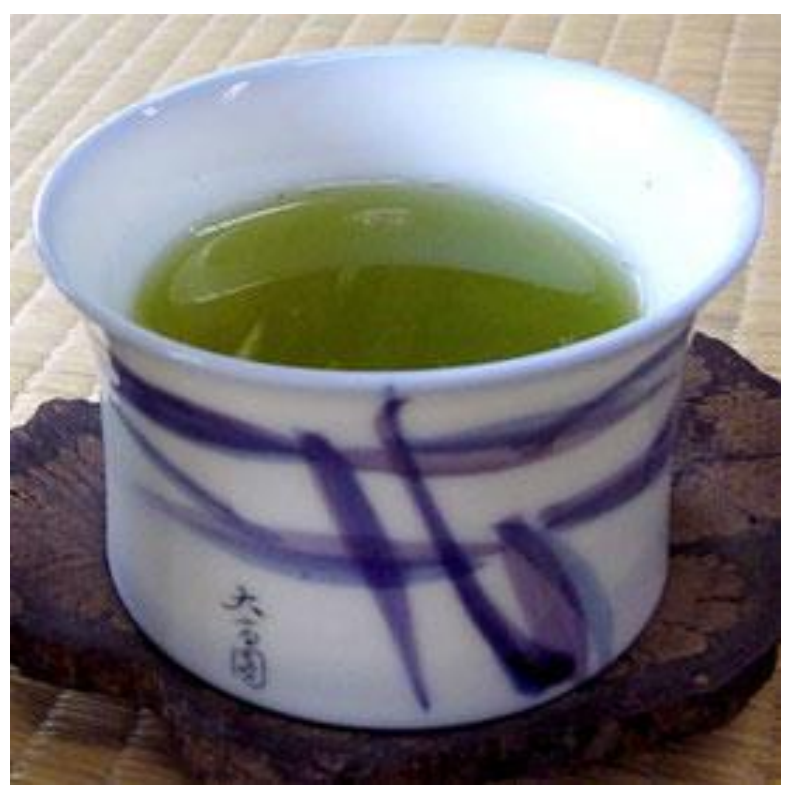

Fig. 13 A nice hot cup of Ino tea.

\section{ENJOY A CUP OF CHUKEI-GONOMI - CHUKEI (INO) STYLE TEA!}




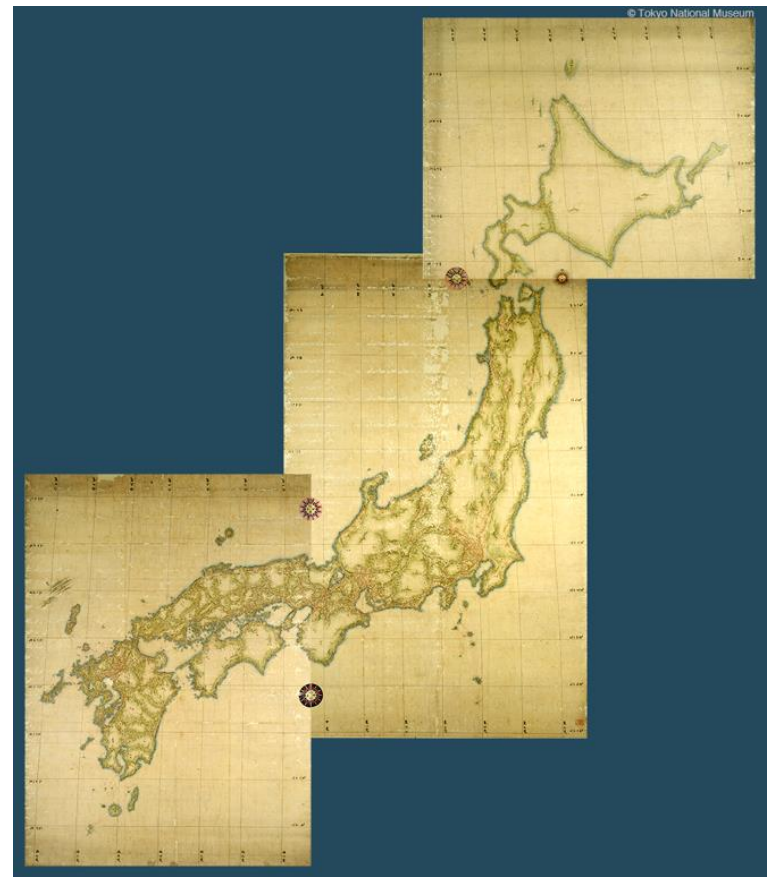

Fig. 14 The smallest version of Ino's Map of Japan of $1821 @$ $1: 432,000$ in three sheets.

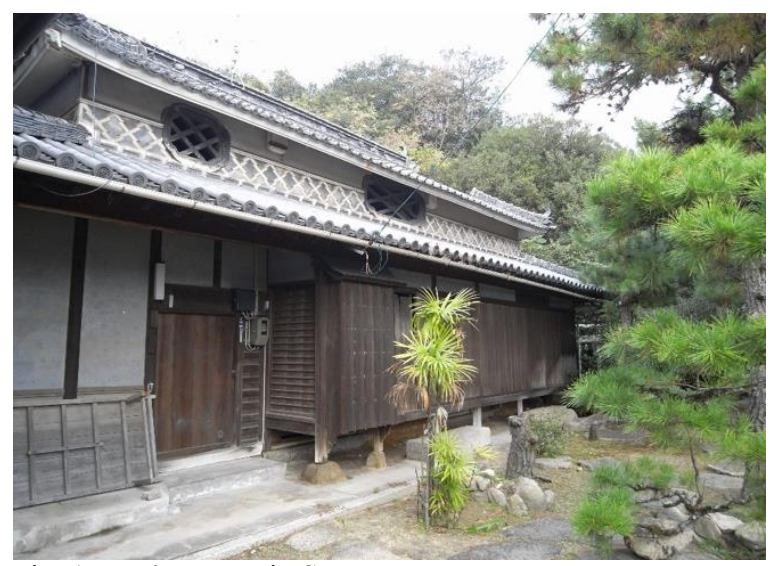

Fig. 15 Ino's House in Sawara.

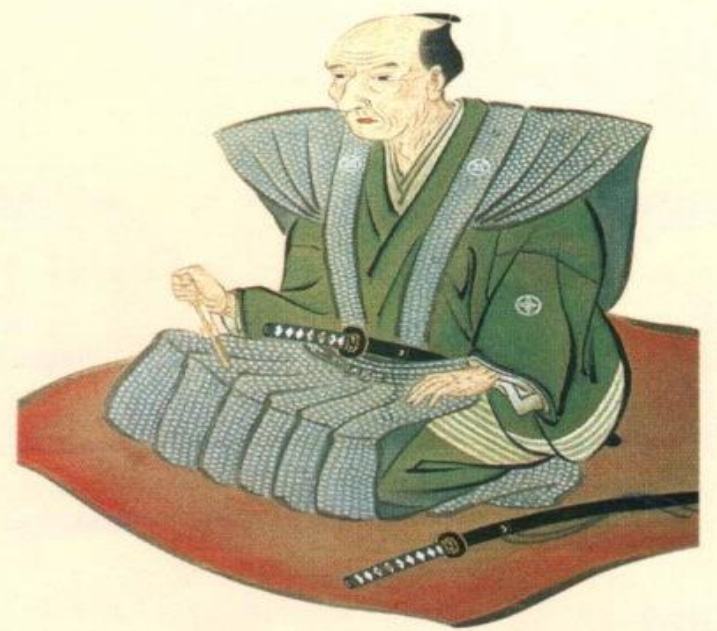

Fig. 16 Famous Japanese Surveyor Ino Tadataka

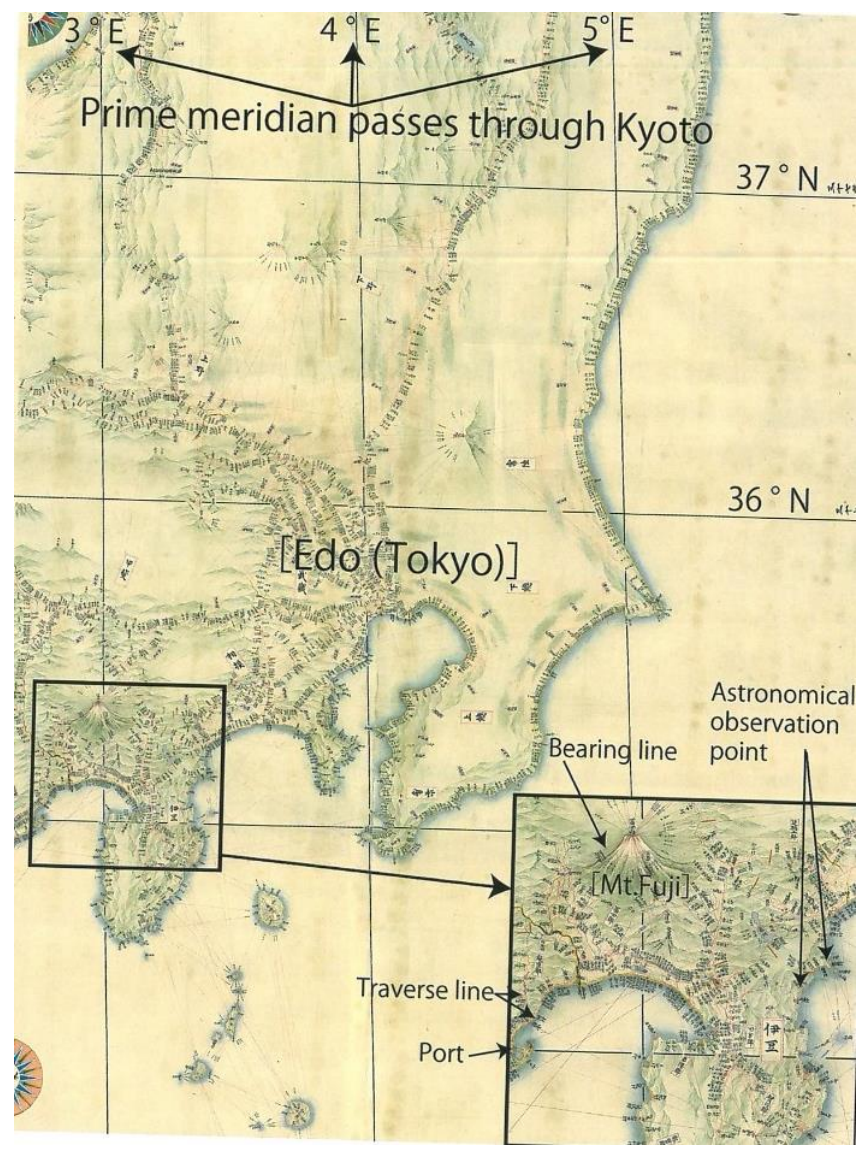

Fig. 17 Detail on the Ino-zu as shown in "Japan and the Dutch (1600-1853)" by Grant Goodman.

\section{References}

Brock, John F. (2000). "Truly Magnetic Variation: True Versus Magnetic North - Can North Become South on the Compass?", $2^{\text {nd }}$ Trans Tasman Surveyors Conference, Queenstown, NZ 2000

Brown, Sanborn. Ino Tadataka: Surveyor, Map Maker, Icon, (Kindle Book)

Goodman, Grant Kohn. (1600-1853). Japan and the Dutch Otani, Ryokichi (1918). A Brief Account of the Life and Work of Tadataka INO, Proceedings of the Imperial Academy Vol. 1, Issue No. 5, pp 171-239

Otani, Ryokichi, (2001). Tadataka Ino - The Japanese Land Surveyor, (Simon Publications)

\section{From the Internet:}

Jonkers, Art R.T., Jackson, Andrew and Murray, Anne, (American Geophysical Union, 2003). Four Centuries of Geomagnetic Data From Historical Records, Reviews of Geophysics 